\title{
Angiosarcoma of the Soft Palate - A Case Report
}

Venkatesh G Naikmasur, Atul P Sattur and Biyas Bhowmik ${ }^{*}$

Department of Oral Medicine and Radiology, S.D.M. College of Dental Sciences and Hospital, Sattur, Dharwad, Karnataka, India

*Corresponding author: Biyas Bhowmik, Post-Graduate, Department of Oral Medicine and Radiology, S.D.M. College of Dental Sciences and Hospital, Sattur, Dharwad, Karnataka, India, Tel: 00918348067713; E-mail: biyas9bhowmik@gmail.com

Rec date: Jan 27, 2015, Acc date: Feb 26, 2015, Pub date: Feb 28, 2015

Copyright: (c) 2015 Naikmasur VG, et al. This is an open-access article distributed under the terms of the Creative Commons Attribution License, which permits unrestricted use, distribution, and reproduction in any medium, provided the original author and source are credited.

\begin{abstract}
Angiosarcoma of the head and neck is a rare malignant neoplasm. Approximately $50 \%$ of angiosarcomas occur in the head and neck; however occurrence of angiosarcoma in the oral cavity is extremely rare. This case report presents clinical, Computed Tomography (CT) and histopathological findings of a case of angiosarcoma of the soft palate. The malignant tumor occurred in a 56-year-old man who reported with pain and difficulty in swallowing food. An incisional biopsy was done. In the mean time, patient was advised CT Scan to know the extent of the tumor. Based on clinical features, CT and histopathology reports, a diagnosis of angiosarcoma were made.
\end{abstract}

Keywords: Angiosarcoma; Soft Palate; CT scan; Histopathology

\section{Introduction}

'Skepticism is a healthy response to diagnosis of any tumor as angiosarcoma.'(Lane, 1952)[1]. Despite the ubiquitous nature of blood vessels throughout the human body and the relatively common occurrence of benign vascular tumors, one rarely comes across malignant tumors of vasoformative mesenchyme [2]. Angiosarcoma is a malignant neoplasm of endothelial-type cells that line vessel walls. In the head and neck region, the most common site of its occurrence is the scalp [3]. It is a highly malignant tumor accounting for less than $0.1 \%$ of head and neck malignancies although approximately $50 \%$ of Angiosarcomas occur in the head and neck region [4]. It is characterized by rapidly proliferating, extensively infiltrating anaplastic cells derived from blood vessels and lining irregular bloodfilled spaces. This article aims at reporting on the clinicohistopathological features and Computed Tomography (CT) findings of primary angiosarcoma of the soft-palate.

\section{Case}

A 56 year old male patient reported with a complaint of severe, continuous and throbbing pain in the right lower jaw since 2 months. Patient had difficulty in swallowing food, reduced appetite and history of weight loss since the same duration. Past medical history revealed an episode of heart attack 1 year back and history of asthma since 8 years- for which patient was already on medications.

Extra-oral examination revealed enlarged right submandibular and jugulo-digastric lymphnodes, tender and firm to hard in consistency. Intra-oral examination revealed a diffuse swelling involving the soft palate on the right side (Figure 1). It was extending from the pterygomandibular raphe to the anterior faucial pillars involving the uvula and measuring approximately $4 \mathrm{~cm} \times 3 \mathrm{~cm}$. The borders were indistinct and the overlying mucosa was erythematous. Routine blood investigations revealed normocytic normochromic anaemia of 13.9 $\mathrm{g} / \mathrm{dl}$ and a platelet count of 3.13 lakhs/ cumm.

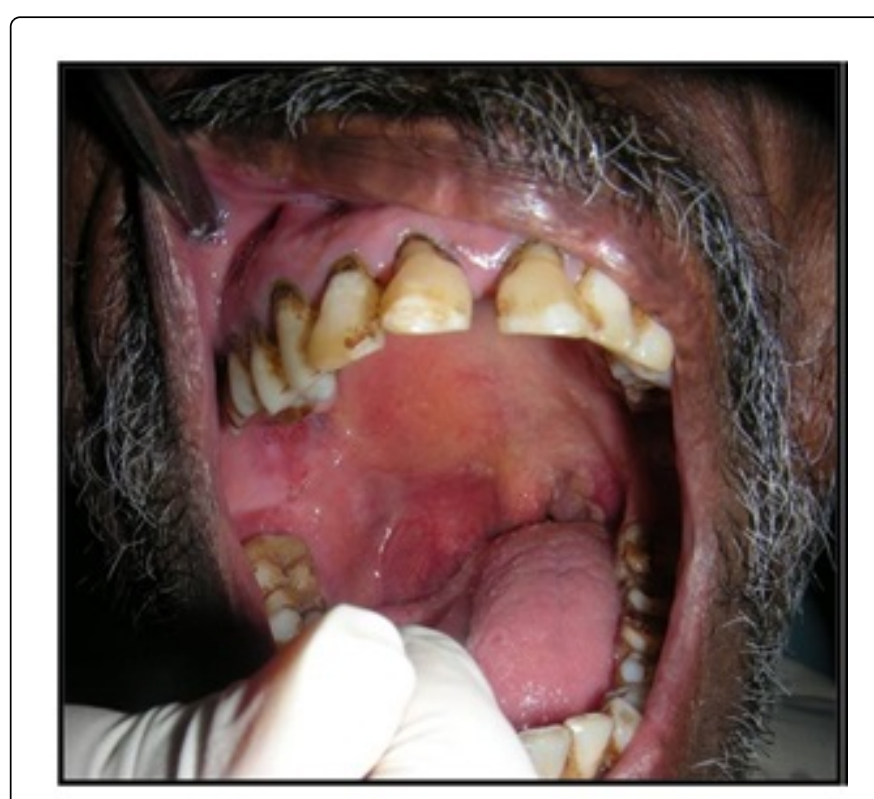

Figure 1: First visit: A diffuse swelling on the right side of soft palate of the patient.

Initially a fine needle aspiration biopsy done did not yield diagnostic results. So, an open incisional biopsy was performed to obtain the diagnostic material. There was massive bleeding from the soft-tissue mass. Post-biopsy, a compressive dressing was given to prevent post-operative hematoma. Also, the patient was advised soft diet for 2 weeks. The biopsy specimen subjected to Hematoxylin \& Eosin staining. The histopathology reported highly dysplastic cells with abundant cytoplasm and hyperchromatic nuclei, lining the alveolar vascular channels. Stromal hyalinization was seen between tumor cells. Areas of necrosis and hemorrhage were also evident. These findings were suggestive of angiosarcoma of the soft palate (Figure $2 \mathrm{a}$ and $2 \mathrm{~b}$ ). 
Citation: Naikmasur VG, Sattur AP, Bhowmik B (2015) Angiosarcoma of the Soft Palate - A Case Report. J Cytol Histol S3: 001. doi:

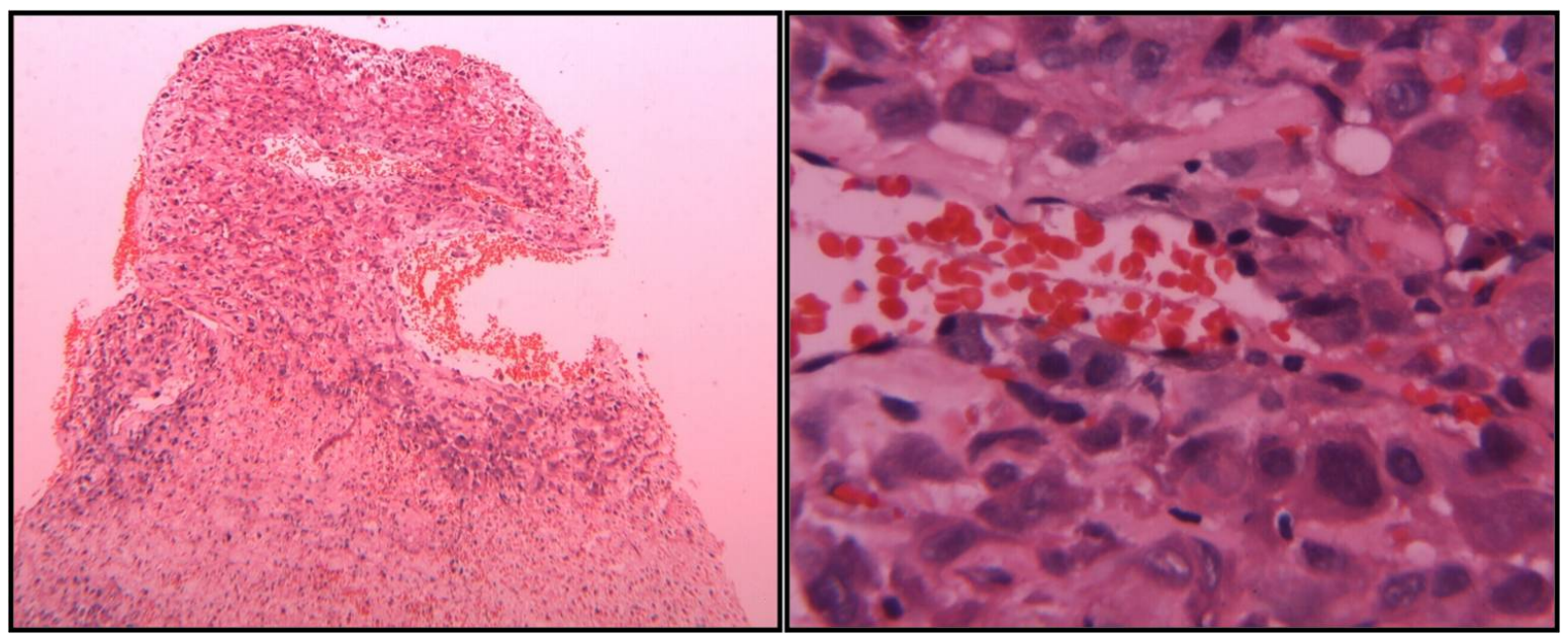

Figure 2: A) Multiple vascular channels and areas of hemorrhage of tumor mass. Stromal hyalinization seen between the tumor cells. (hematoxylin-eosin, 40X). B) Highly dysplastic cells with abundant eosinophilic nuclei lining a vascular channel (hematoxylin-eosin, 400X).

The patient was advised CT Scan to know the extent of the lesion and lymphnode involvement. CT revealed a well-defined heterogeneously enhancing mass predominantly occupying the prestyloid compartment of para-pharyngeal space with multiple non- enhancing necrotic areas. Cortical thinning of the lingual surface of ramus, angle and condylar process was seen with areas of erosion (Figure $3 \mathrm{a}$ and $3 \mathrm{~b}$ ).
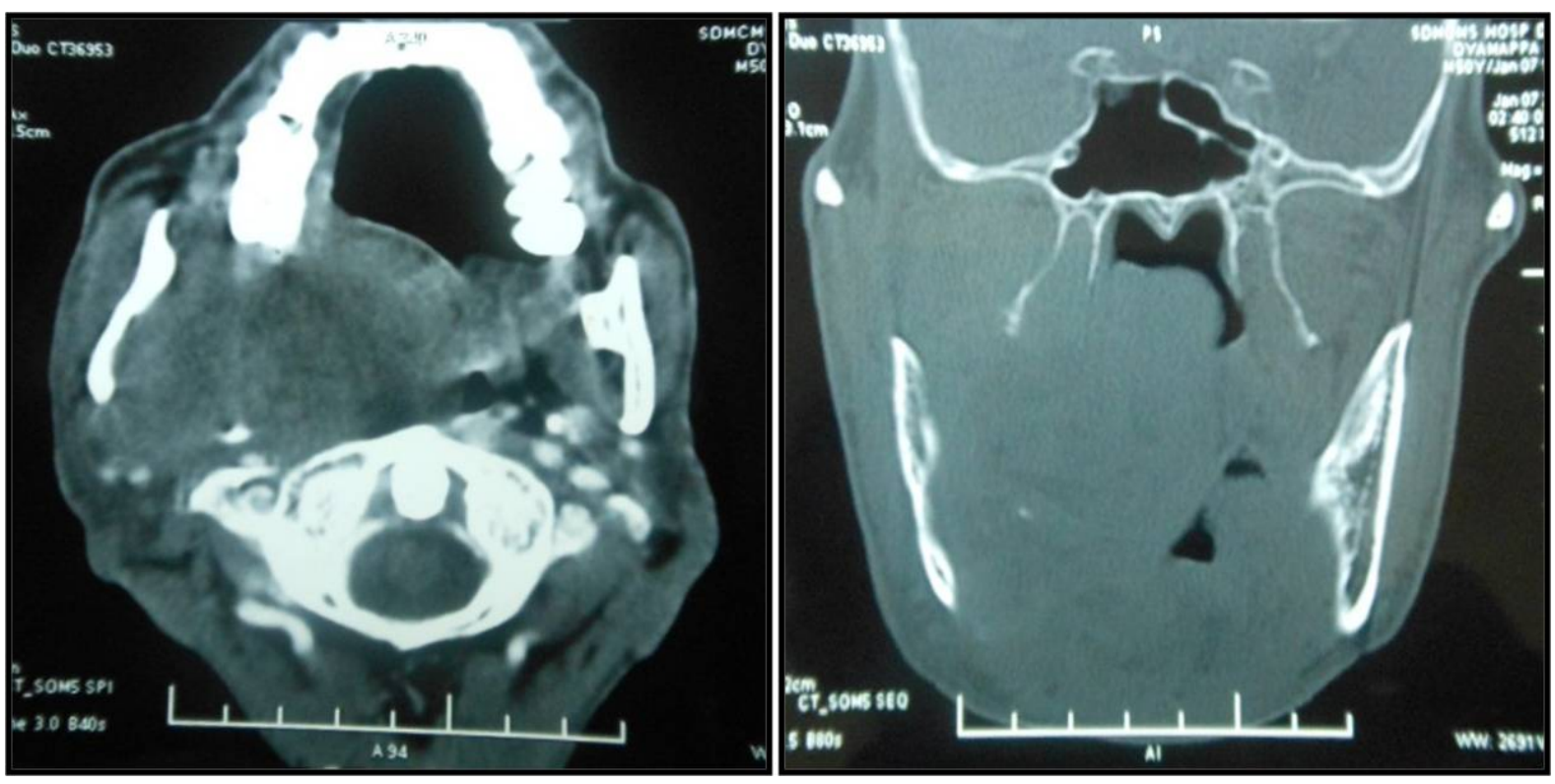

Figure 3: A) Axial CT with contrast showing a well-defined heterogeneously enhanced soft tissue mass involving the masticator and parapharyngeal spaces, causing anterior and lateral displacement of ramus and angle of the mandible on right side and predominantly compromising the oro-pharyngeal airway column. B) Bone window section of CT showing cortical thinning and erosion of the lingual surface of ramus and angle of the mandible on the right side. Medially, the mass is displacing the lateral pharyngeal wall and involving the pterygopalatine fossa with significant narrowing of naso and oro-pharyngeal airway column.

Three weeks later patient reported again with severe pain, inability to swallow food and spontaneous bleeding from the mouth while having food. Patient was severely emaciated. The lymphnodes were increased in size and fixed to the underlying structures. To our surprise on intra-oral examination, we noticed another swelling on the left faucial pillar region apart from the rapid increase in size of the swelling on the right side. Both the swellings were encroaching into the para-pharyngeal space narrowing the oro-pharyngeal aperture. Sloughing and blood clots were observed over the swelling (Figure 4). 


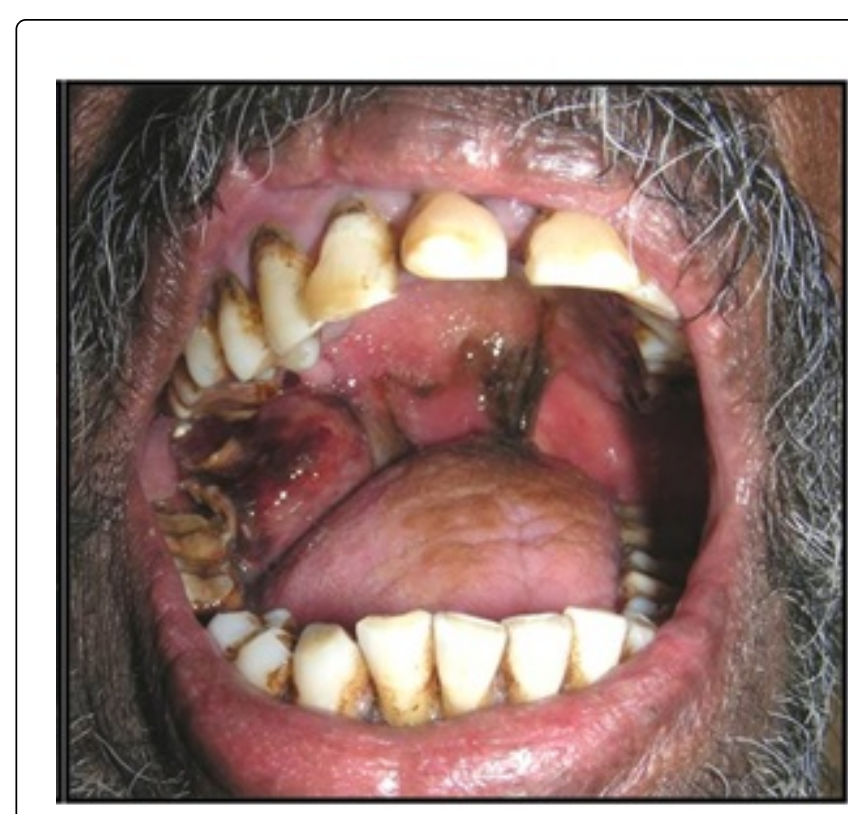

Figure 4: Subsequent visit after 3 weeks: revealed bilateral swellings of the soft palate with areas of haemorrhage and ecchymosis, encroaching into the oro-pharyngeal space.

Considering the severely debilitated state of the patient, he was immediately admitted to the hospital. Treatment was started with combination chemotherapy regimen of gemcitabine and docetaxel and fractionated Intensity Modulated Radiation Therapy was planned. However, he succumbed to death with a massive myocardial infarction within 2 days.

\section{Discussion}

The word sarcoma is a slanted adaptation of the Greek word sarkoma, which means "fleshy growth". Head and Neck Angiosarcomas occuring in the oral cavity may be the primary tumors or metastatic deposits from other areas in the body [3]. These highly aggressive mesenchymal tumors arise in association with a preexisting clinical condition such as chronic lymphedema or previous irradiation or as a de novo occurrence [5].

Cutaneous angiosarcomas are most common. Other common presentations include primary breast angiosarcomas, angiosarcomas secondary to long-standing lymphedema of the adjacent arm following radical mastectomy (Stewart-Treves Syndrome), angiosarcomas of the deep soft tissue, radiation-induced angiosarcoma and angiosarcoma associated with foreign material [1]. Angiosarcomas of head and neck usually occur in the elderly population, peak incidence being in the seventh decade of life, with a male predilection [6,7]. Angiosarcoma of the oral cavity may occur in various tissues, such as oral soft tissue, minor salivary glands, and bones [7-9]. Patients mostly report at advanced stages with symptoms and signs of pain, fatigue, weight loss, skin or intraoral lesion, bone pain, abnormal bleeding, enlarged lymph nodes, anemia, pathologic fractures, chest pain and difficulty in breathing. Intraorally, it can present as well or ill-defined, polypoid or nodular reddish, bluish or violet mass, soft to fibrous in consistency. Mucosal ulceration is not uncommon and associated with edema and bleeding on palpation $[6,7,10]$. They are often misdiagnosed at an early stage leading to poor prognosis and a high mortality rate. As per our Medline search (1975-2012), there is only one reported case on angiosarcoma of the soft palate where primary angiosarcoma of soft palate occurred in a 16 year old male[11].

Fanburg-Smith et al. [11] reported 22 cases of primary angiosarcoma of the oral and salivary glands. The sites of the 22 cases were tongue (9), parotid gland (4), lip (4), submandibular gland (3), hard palate (1) and soft palate (1). Males and females were almost equally affected. The size of tumors of all 29 cases ranged from $0.8-7.0$ $\mathrm{cm}$. Histologically, they were vasoformative, $86 \%$ (25 cases) had solid and $17 \%$ (5 cases) had distinctive papillary areas. Histologically, it was a low grade tumor comprising of focal epithelioid, papillary and solid areas. Our case is the second reported case of angiosarcoma occurring in the soft palate with an approximate size of $4 \mathrm{~cm} \times 3 \mathrm{~cm}$. The tumor showed nuclear atypia and highly dysplastic cells lining the alveolar vascular channels along with areas of necrosis and hemorrhage suggestive of malignant nature of the tumor.

Angiosarcoma is highly aggressive and has worst prognosis amongst malignant tumors because of high rate of recidivation and potential to metastasize: regionally to the lymph nodes and distantly to the lung, liver and spleen while the central nervous system and heart are rarely affected $[12,13]$. Prognosis for primary oral angiosarcomas depends on the degree of cellular differentiation and the clinical size of the tumor. The time at which the patient reports with clinical presentation is also essential. In this case, the patient reported lateafter 2 months.

The multidisciplinary treatment planning for this highly aggressive tumor includes surgery and radiotherapy with adjuvant chemotherapy. Surgery is the standard treatment for all patients with angiosarcomas of the maxilla or mandible (involving the alveolar ridges). They are treated by wide surgical excision to histologically negative, tumor-free margins, whenever possible. However, this tumor has numerous and irregular vascular channels which are evident only at the microscopic level. Hence, surgical resection is preceded or followed by brachytherapy or external beam radiotherapy to prevent local recurrence. Boron Neutron Capture therapy, a tumorcell targeted radiotherapy and superior to conventional radiotherapies in principle, can be used for recurrent and advanced cases $[7,8,14]$. Angiosarcoma of the maxillary sinus has been treated by cytoreductive surgery followed by postoperative radiotherapy using cyberknife [15]. The role of adjuvant chemotherapy in treating angiosarcomas has been scarcely defined. Antineoplastic agents such as Doxorubicin, Ifosfamide and Gemcitabine have been used in oral as well as injectable forms. Newest trend of treatment involves "Targeted Therapy" which is based on targeting tumor angiogenesis stimulators such as Vascular Endothelial Growth Factor (VEGF) and Epidermal Growth Factor Receptor (EGFR). Bevacizumab(Avastin), Gefitinib (ZD1839, IressaTM) can be used in conjunction with anti-mitotic agents such as docetaxel and paclitaxel [16-18].

Immunohistochemical assay is a useful diagnostic tool for angiosarcoma. The tumor cells are almost always positive for Factor VIII-related antigen, CD31 and CD34 which are endothelial markers [19].

Differential diagnosis includes malignant vascular tumors, such as epithelioid hemangioendothelioma, malignant myopericytoma, Kaposi's sarcoma, spindle cell carcinoma, malignant melanoma, intravascular endothelial hyperplasia and epithelioid angiosarcoma. The current tumor is different from epithelioid 
hemangioendothelioma which shows epithelioid tumor cells with intracytoplasmic lumen formation and few mitotic figures. It is also different from malignant myopericytoma histologically which shows concentric, perivascular arrangement of plump spindle to round myxoid cells which are positive for alpha smooth muscle actin.

The presence of red cell extravasation and anastomosing vascular spaces, which may be focal, distinguishes Angiosarcoma from Kaposi's sarcoma. Spindle cell carcinoma exhibits distinct cytokeratin positivity, not positive for endothelial markers (e.g. CD 31, CD 34 and F VIII RA). Malignant Melanoma is positive for HMB 45 and shows S-100 immunoreactivity. Again this tumor is different from intravascular endothelial hyperplasia which shows lack of features like cellular atypia, necrotic areas, invasion of perivascular spaces and existence of solid areas with or without vascular differentiation. Epithelioid angiosarcomas are distinguished by presence of cytokeratin expression. Histologically, sheets of pleomorphic, round to polygonal epithelioid cells and occasional cells with intracytoplasmic lumina containing erythrocytes can usually be identified.

In the literature, the follow-up on the primary oral angiosarcomas is either largely unknown or favorable, with a few exceptional cases. Many primary oral angiosarcoma patients died from unrelated causes such as heart disease (as seen in our case) or treatment-related death shortly after treatment of their tumor or were lost to follow-up. Patients with a longer follow-up period had relatively good outcomes [20-24].

\section{Conclusion}

Angiosarcoma is a rapidly progressing malignancy that rarely affects the oral and pharyngeal mucosa. Prognosis is generally considered to be rather poor, although the size (and hence stage) of the tumor, its site and the histopathologic grade may influence survival [25-28]. Encountering such lesions in the oral cavity is of great concern for the dentist. In this case, the inaccessible site of the lesion posed difficulty during the biopsy procedure. Also, investigations though initiated without delay, the patient's lack of awareness and efforts to fight against the existing tumor, illiteracy, poverty, and lack of family support ended up in a grave disaster. Once diagnosed, the treatment was initiated immediately considering the rapid growth and invasive behaviour of the lesion. The tumor was definitely responsible for the emaciated state of the patient; however the doctor decreed that the sudden demise was due to myocardial infection. Suggestions for autopsy to ascertain the cause of death were declined by the patient's relatives.

\section{References}

1. Andersen NJ, Nickoloff BJ, Dykema KJ, Boguslawski EA, Krivochenitser RI, et al. (2013) Pharmacologic inhibition of MEK signaling prevents growth of canine hemangiosarcoma. Mol Cancer Ther 12: 1701-1714.

2. Wesley RK, Mintz SM, Wertheimer FW (1975) Primary malignant hemangioendothelioma of the gingiva. Report of a case and review of the literature. Oral Surg Oral Med Oral Pathol 39: 103-112.

3. Carr RJ, Green DM (1986) Oral presentation of disseminated angiosarcoma. Br J Oral Maxillofac Surg 24: 277-285.

4. Sturgis EM, Potter BO (2003) Sarcomas of the head and neck region. Curr Opin Oncol 15: 239-252.

5. Govender PS (2009) Atypical presentation of angiosarcoma of the scalp in the setting of human immunodeficiency virus (HIV). World J Surg Oncol 7: 99.
6. Meis-Kindblom JM, Kindblom LG (1998) Angiosarcoma of soft tissue: a study of 80 cases. Am J Surg Pathol 22: 683-697.

7. Favia G, Lo Muzio L, Serpico R, Maiorano E (2002) Angiosarcoma of the head and neck with intra-oral presentation. A clinico-pathological study of four cases. Oral Oncol 38: 757-762.

8. Loudon JA, Billy ML, DeYoung BR, Allen CM (2000) Angiosarcoma of the mandible: a case report and review of the literature. Oral Surg Oral Med Oral Pathol Oral Radiol Endod 89: 471-476.

9. Abdullah BH, Yahya HI, Talabani NA, Alash NI, Mirza KB (2000) Gingival and cutaneous angiosarcoma. J Oral Pathol Med 29: 410-412.

10. Uchiyama Y, Murakami S, Kishino M, Furukawa S (2009) A case report of primary gingival angiosarcoma. Oral Surg Oral Med Oral Pathol Oral Radiol Endod 108: e17-21.

11. Fanburg-Smith JC, Furlong MA, Childers EL (2003) Oral and salivary gland angiosarcoma: a clinicopathologic study of 29 cases. Mod Pathol 16: 263-271.

12. Florescu M, Simionescu C, MÄfrgÄfritescu C, Georgescu CV (2005) Gingival angiosarcoma: histopathologic and immunohistochemical study. Rom J Morphol Embryol 46: 57-61.

13. Dummer R, Pittelkow MR, Iwatsuki K, Green A, Elwan NM (2011) Skin Cancer- A World-Wide Perspective. (1stedn) Berlin, Heidelberg: Springer, USA.

14. Kato I, Fujita Y, Maruhashi A, Kumada H, Ohmae M, et al. (2009) Effectiveness of boron neutron capture therapy for recurrent head and neck malignancies. Appl Radiat Isot 67: S37-42.

15. Yokoawa M, Tanaka S, Niwa H, Makiyam Y, Hirayama T, et al. (2011) Angiosarcoma of maxillary sinus:A case report. Oral Oncol 47: S74-S156.

16. Mankin HJ, Hornicek FJ (2005) Diagnosis, classification, and management of soft tissue sarcomas. Cancer Control 12: 5-21.

17. Koontz BF, Miles EF, Rubio MA, Madden JF, Fisher SR, et al. (2008) Preoperative radiotherapy and bevacizumab for angiosarcoma of the head and neck: two case studies. Head Neck 30: 262-266.

18. Kirby AM, A'Hern RP, D'Ambrosio C, Tanay M, Syrigos KN, et al. (2006) Gefitinib (ZD1839, Iressa) as palliative treatment in recurrent or metastatic head and neck cancer. Br J Cancer 94: 631-636.

19. Yang XJ, Zheng JW, Zhou Q, Ye WM, Wang YA, et al. (2010) Angiosarcomas of the head and neck: a clinico-immunohistochemical study of 8 consecutive patients. Int J Oral Maxillofac Surg 39: 568-572.

20. Frick WG, McDaniel RK (1988) Angiosarcoma of the tongue: report of a case. J Oral Maxillofac Surg 46: 496-498.

21. Albright CR, Shelton DW, Vatral JJ, Hobin FC (1970) Angiosarcoma of the gingiva: report of case. J Oral Surg 28: 913-917.

22. Oliver AJ, Gibbons SD, Radden BG, Busmanis I, Cook RM (1991) Primary angiosarcoma of the oral cavity. Br J Oral Maxillofac Surg 29: 38-41.

23. Piscioli F, Leonardi E, Scappini P, Cristofolini M (1986) Primary angiosarcoma of the gingiva. Case report with immunohistochemical study. Am J Dermatopathol 8: 430-435.

24. Tabata M, Sugihara K, Matsui R, Yonezawa S, Abeyama K, et al. (1999) Angiosarcoma of the tongue: report of a case with immunohistochemical findings. J Oral Pathol Med 28: 92-95.

25. Mark RJ, Poen JC, Tran LM, Fu YS, Juillard GF (1996) Angiosarcoma. A report of 67 patients and a review of the literature. Cancer 77: 2400-2406.

26. Mentzel T, Kutzner H, Wollina U (1998) Cutaneous angiosarcoma of the face: clinicopathologic and immunohistochemical study of a case resembling rosacea clinically. J Am Acad Dermatol 38: 837-840.

27. Haustein UF (1991) Angiosarcoma of the face and scalp. Int J Dermatol 30: 851-856.

28. Holden CA, Spittle MF, Jones EW (1987) Angiosarcoma of the face and scalp, prognosis and treatment. Cancer 59: 1046-1057. 